\title{
Three-Phase T-Type qZ Source Inverter With Control Current Associated to a Vectorial Modulator for Photovoltaic Applications
}

\author{
V. Fernão Pires \\ ESTSetúbal, Polytechnic \\ Institute of Setúbal \\ INESC-ID Lisboa \\ Setúbal, Portugal \\ vitor.pires@estsetubal.ips.pt
}

\author{
D. Foito \\ ESTSetúbal, Polytechnic \\ Institute of Setúbal \\ Setúbal, Portugal \\ daniel.foito@estsetubal.ips.pt
}

\author{
A. Cordeiro \\ ISEL - Polytechnic Institute \\ of Lisboa \\ Lisboa, Portugal \\ acordeiro@deea.isel.ipl.pt
}

\author{
J. F. Martins \\ CTS/UNINOVA \\ FCT/UNL \\ Caparica, Portugal \\ jf.martins@fct.unl.pt
}

\begin{abstract}
This paper presents a fast and robust control system for a three-phase quasi-Z-source inverter (qZSI) connected to the grid. The topology combines two quasi-Z-source networks with a T-type inverter allowing to obtain AC voltages with multilevel characteristics and properties of the referred networks. To control this system a closed-loop current controller for the AC currents is proposed. The controller is based on a vectorial modulator associated to the shoot-through states. The DC-link voltage is maintained stable at the reference value by adjusting the shoot-through duty cycle. The controller is characterized by fast transient response and robustness to parameter and load variations. In order to confirm the desired characteristics and performance of the converter and control system several simulation tests were performed.
\end{abstract}

Keywords-T-Type converter; $q Z$ voltage source inverter; current controller; shoot-through states.

\section{INTRODUCTION}

Renewable energy sources play a fundamental role in the actual context. Such energy sources generally require power electronic converters associated to these systems to obtain the maximum power as well as an appropriate interconnection with the electrical grid. Due to the different characteristics and specificities of the several renewable sources and applications, the choice of the power converter topology and associated control system must be done very carefully.

One of the specificities that are usually required by photovoltaic sources connected to the electrical grid is the requirement of a power converter with voltage boost characteristics. In order to fulfill this requirement there are different solutions, most of them based on single or double stage conversion [1-3]. In single stage conversion it can be used a low frequency transformer between the inverter and the grid [4-6]. Another solution is based on the application of several photovoltaic panels associated to a multilevel inverter such as the cascaded H-bridge [7-9]. Besides the capability to extend the $\mathrm{AC}$ voltage this last solution also provides the advantages of multilevel converters. Regarding double stage conversion, one of the most common solutions is based on two converters, a DC/DC converter and DC/AC converter. The
DC/DC stage normally uses a Boost type DC/DC converter or a topology with a high frequency transformer associated to a maximum power point tracking algorithm [10-12].

Other types of power converters can be used on photovoltaic grid-connected systems. One interesting solutions that has been proposed and studied in the last years is through the integration of a qZSI connected to the grid. This converter combines a qZ-source network with a classical voltage source inverter. One of the main characteristics of this converter that makes it suitable for this kind of application is the Boost feature provided by the special shoot-through state. Furthermore, the shoot-through state provides additional protection to short-circuit failure of power devices. Thus, many works related with single and three-phase qZSI and respective control system were proposed for this type of application [1316]. Due to the characteristics of these converters, they were also expanded to multilevel applications. In this context, several works have been focused in the quasi- $Z$ neutral-pointclamped converter [17-19]. Regarding control strategies, several solutions have been applied, such as, sinusoidal pulsewidth modulation (SPWM) or the space vector modulation techniques. Other solutions based on current controller have also been proposed. A hysteresis current control for $\mathrm{Z}$ and quasi-Z voltage source inverters was also proposed [20,21]. However, this technique was also applied to the two-level single-phase inverter. Another proposed multilevel qZSI solution for photovoltaic applications is based on the cascaded H-bridge inverter topology [22,23]. Recently the use of a multilevel qZSI based on the T-type inverter was also proposed [24]. To control this converter was proposed sinusoidal pulsewidth modulation.

This paper proposes a fast and robust closed-loop control solution for a three-phase multilevel qZSI topology based on the T-type inverter. The proposed solution allows to control the AC currents through a multilevel hysteretic current controller and vectorial modulator combined with the shoot-through state to provide the necessary step-up voltage. This modulator was also developed in order to maintain the stability of DC voltages. Several simulation testes will be performed in order 
to test the proposed system. From the obtained results of these tests is possible to confirm the referred characteristics.

\section{SYSTEM CONTROL OF THE MULTILEVEL QZSI WITH T-TYPE CONVERTER}

The three-phase T-type qZSI uses a combination of two qZ impedance source networks with a three-level inverter. This inverter is characterized by a combination of a classical threephase inverter with three bidirectional switches connected between the AC terminals and the common DC point of the $\mathrm{qZ}$ impedance source networks. Fig. 1 shows this topology connected to the three-phase grid through a three-phase inductors system.

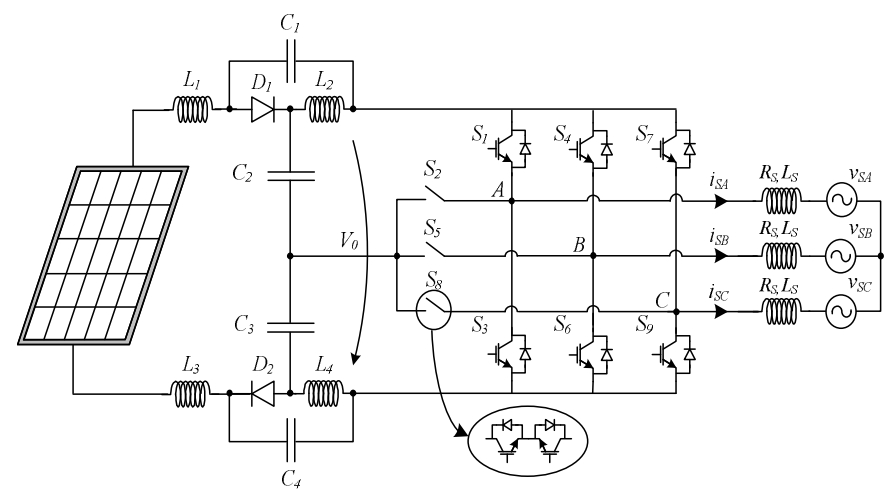

Fig. 1. Grid-connected qZ Source Inverter with T-Type Converter.

The presented system will be described through their state model. This model is described by the system state variables. Analyzing firstly the inverter it is possible to verify that the AC voltages are function of the switches state. The switches, $S_{i j}$, of converter can be associated to a discrete variable function, $G i$, as described by (where $i=\mathrm{A}, \mathrm{B}, \mathrm{C}$ are the phases of the converter and $j=1,4,7)$ :

$$
G_{i}=\left\{\begin{array}{cc}
1 \quad \text { if } S_{j} \text { is on } \wedge S_{j+1} \text { is off } \wedge S_{j+2} \text { is off } \\
0,5 \text { if } S_{j} i s \text { off } \wedge S_{j+1} i s \text { on } \wedge S_{j+2} i s \text { off } \\
0 \quad\left(\text { if } S_{j} \text { isoff } \wedge S_{j+1} i \text { off } \wedge S_{j+2} \text { ison }\right) \vee \\
\quad\left(\text { if } S_{1,2,3} \text { ison } \vee S_{4,5,6} \text { ison } \vee S_{7,8,9} i \text { son }\right)
\end{array}\right.
$$

Tacking into consideration the $\mathrm{AC}$ voltages as a function of the states of the switches, these voltages will be given by:

$$
\left[\begin{array}{l}
V_{A} \\
V_{B} \\
V_{C}
\end{array}\right]=V_{o}\left[\begin{array}{lll}
1 & 0 & 0 \\
0 & 1 & 0 \\
0 & 0 & 1
\end{array}\right]\left[\begin{array}{l}
G_{A} \\
G_{B} \\
G_{C}
\end{array}\right]
$$

Where $V o$ represents the output voltage of the qZ-Source inverter; $V A, V B$ and $V C$ are the phase-to-neutral voltage of phases $\mathrm{A}, \mathrm{B}$ and $\mathrm{C}$ respectively;
Regarding the upper and lower DC currents of the inverter they are dependent of the shoot-through state as can be seen by Fig. 2.

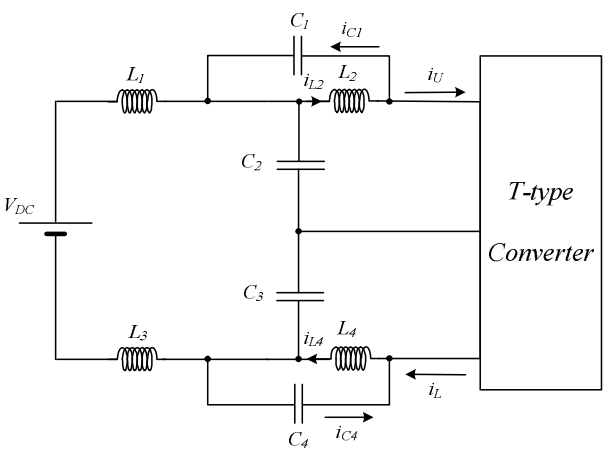

a)

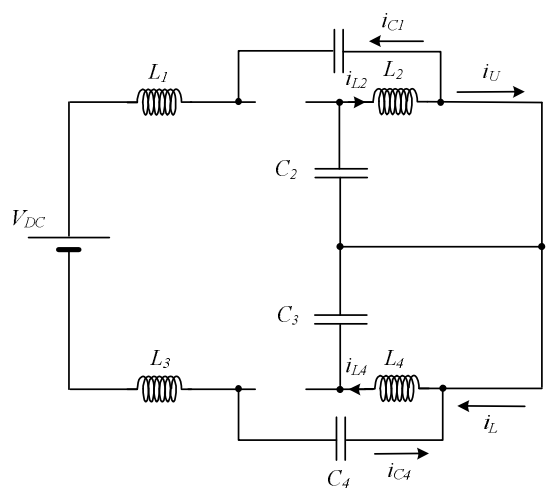

b)

Fig. 2. Equivalent circuits of the converter: a) active state state and b) shootthrough state.

During the shoot-through state the upper and lower DC currents of the inverter are dependent of the two qZ impedance source networks. In this state these currents, according with Fig.2, can be given by:

$$
\left\{\begin{array}{l}
i_{U}=i_{L 2}-i_{C 1} \\
i_{L}=i_{L 4}-i_{C 4}
\end{array}\right.
$$

For the other state condition these currents are function of the AC currents of each phase (iSA, iSB, iSC) and the state of the switches. Thus, they can be described by:

$$
\left[\begin{array}{c}
i_{U} \\
i_{L}
\end{array}\right]=\left[\begin{array}{ccc}
\operatorname{round}\left(G_{A}-0,1\right) & \operatorname{round}\left(G_{B}-0,1\right) & \operatorname{round}\left(G_{C}-0,1\right) \\
1-\operatorname{round}\left(G_{A}\right) & 1-\operatorname{round}\left(G_{B}\right) & 1-\operatorname{round}\left(G_{C}\right)
\end{array}\right]\left[\begin{array}{c}
i_{S A} \\
i_{S B} \\
i_{S C}
\end{array}\right]
$$

Taking into consideration the AC load presented in Fig.1 and the state of the switches the following equation is obtained: 


$$
\begin{aligned}
& {\left[\begin{array}{c}
\frac{d i_{A}}{d t} \\
\frac{d i_{B}}{d t} \\
\frac{d i_{C}}{d t}
\end{array}\right]=\left[\begin{array}{ccc}
-\frac{R_{S}}{L_{S}} & 0 & 0 \\
0 & -\frac{R_{S}}{L_{S}} & 0 \\
0 & 0 & -\frac{R_{S}}{L_{S}}
\end{array}\right]\left[\begin{array}{c}
i_{S A} \\
i_{S B} \\
i_{S C}
\end{array}\right]+} \\
& {\left[\begin{array}{ccc}
\frac{2 V_{o}}{3 L_{S}} & -\frac{V_{o}}{3 L_{S}} & -\frac{V_{o}}{3 L_{S}} \\
-\frac{V_{o}}{3 L_{S}} & \frac{2 V_{o}}{3 L_{S}} & -\frac{V_{o}}{3 L_{S}} \\
-\frac{V_{o}}{3 L_{S}} & -\frac{V_{o}}{3 L_{S}} & -\frac{2 V_{o}}{3 L_{S}}
\end{array}\right]\left[\begin{array}{c}
G_{A} \\
G_{B} \\
G_{C}
\end{array}\right]-\left[\begin{array}{ccc}
\frac{1}{L_{S}} & 0 & 0 \\
0 & \frac{1}{L_{S}} & 0 \\
0 & 0 & \frac{1}{L_{S}}
\end{array}\right]\left[\begin{array}{l}
V_{S A} \\
V_{S B} \\
V_{S C}
\end{array}\right]}
\end{aligned}
$$

Where $R_{S}$ and $L_{S}$ are the load resistance and load inductance and $V S A, V S B$ and $V S C$ are the grid voltages;

This last equation can be converted into the $\alpha \beta$ referential through the Clark Concordia transformation, as presented in equation (6).

$$
\begin{aligned}
{\left[\begin{array}{c}
\frac{d i_{\alpha}}{d t} \\
\frac{d i_{\beta}}{d t}
\end{array}\right]=} & {\left[\begin{array}{cc}
-\frac{R_{S}}{L_{S}} & 0 \\
0 & -\frac{R_{S}}{L_{S}}
\end{array}\right]\left[\begin{array}{c}
i_{\alpha} \\
i_{\beta}
\end{array}\right]+\left[\begin{array}{cc}
\frac{V_{o}}{L_{S}} & 0 \\
0 & \frac{V_{o}}{L_{S}}
\end{array}\right]\left[\begin{array}{l}
G_{\alpha} \\
G_{\beta}
\end{array}\right] } \\
& -\left[\begin{array}{cc}
\frac{1}{L_{S}} & 0 \\
0 & \frac{1}{L_{S}}
\end{array}\right]\left[\begin{array}{l}
V_{S \alpha} \\
V_{S \beta}
\end{array}\right]
\end{aligned}
$$

The DC voltages are obtained taking into consideration the two qZ impedance networks and the shoot-trough state. In fact, these voltages will be equal or higher than the photovoltaic panel voltage according the total shoot-through time. Thus, these voltages can be calculated based on it the voltage balance across the inductors. In this analysis is considered that the capacitors are large enough and also $L_{1}=L_{3}, L_{2}=L_{4}$, $C_{1}=C_{4}, C_{2}=C_{3}$. In this condition the DC voltages can be expressed by:

$$
V_{o}=B V_{i}=\frac{1}{1-2 D} V_{i}
$$

where $D$ is the shoot-through duty ratio given by $D=T_{s h} / T, T_{s h}$ is the total shoot-through time interval and $T$ the switching period.

The AC voltages of the inverter can be represented as a vector in the $\alpha \beta$ coordinate system. Taking into account the switching states there will be 19 different vectors [25]. The obtained different vectors that are function of the switches states are presented in Fig. 3. It must be noted that the shootthrough state corresponds to the 0 vector (null vector).

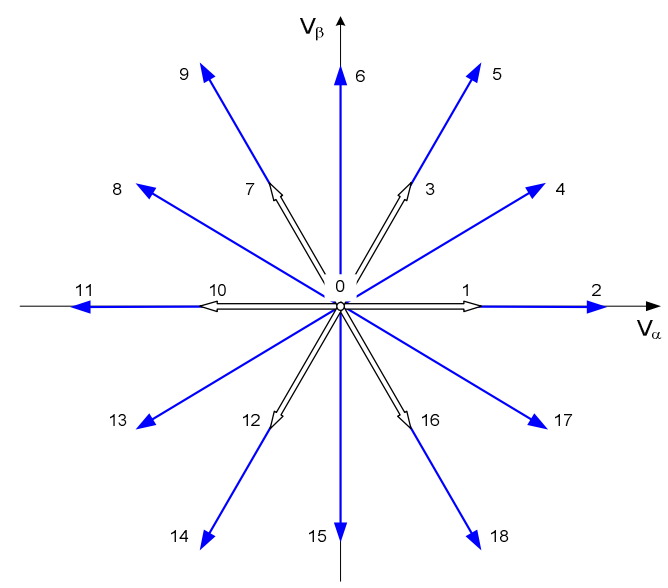

Fig. 3. Different $\mathrm{AC}$ voltage vectors in the $\alpha \beta$ coordinate system for the proposed control strategy.

The goal of the closed loop control system is to maintain injected currents to the grid according with the reference level despite variations of the input or grid voltages. This will be achieved through a multilevel hysteretic current controller and vectorial modulator. The AC currents $\left(i_{S A}, i_{S B}\right.$ and $\left.i_{S C}\right)$ will be controlled by the PWM voltages of the converter. In this case, will be used a control system based on the $\alpha \beta$ coordinate system. Thus, a current controller given by the simple following conditions is given:

$$
\left\{\begin{array}{l}
f_{\alpha}=i_{\text {Saref }}-i_{S \alpha} \\
f_{\beta}=i_{S \beta r e f}-i_{S \beta}
\end{array}\right.
$$

According to this last condition, the voltage vector will be selected. So, if condition $f \alpha$ is positive then a voltage vector with a positive $\alpha$ component should be selected, and viceversa. In the case of $f \beta$ the condition is similar, that is, if $\mathrm{fb}$ is positive then a positive $\beta$ component should be selected. Since there are 27 vectors it is not possible to implement a simple two level hysteresis comparator at the output of the functions defined in (8). Thus hysteresis comparators with more levels are adopted. In fact, if $f \alpha$ and $f \beta$ are positive several vectors can be applied (3, 4 and 5). From the analysis of the vectors is possible to verify that all these vectors have three different values for the $\alpha$ component and two different values for the $\beta$ component. Thus, the vector should be adopted taking into account if the functions are near zero or not. For example, if the difference of functions $f \alpha$ and $f \beta$ are near zero, then vector 3 should be chosen. If function $f \alpha$ is far from zero and $f \beta$ near zero then vector 4 should be chosen. Tacking this into consideration it would be adopted a seven level hysteresis comparator associated to function $f \alpha$ and a five level hysteresis comparator associated to function $f \beta$. 
Another issue regarding the choice of the vectors is related with the balance of the voltages in capacitor $\mathrm{C} 2$ and $\mathrm{C} 3$. In order to ensure the balance of those voltages it must be considered the redundant vectors. In fact, all the interior vectors $(1,3,7,10,12,16)$ have redundant vectors, as can be seen by table I. Thus, these vectors must be selected to balance of the capacitor voltages and the phase current directions. Let's consider the previous example where $f \alpha$ and $f \beta$ are positive and $i_{S A}$ and $i_{S C}$ are positive and $i_{S B}$ is negative. For this condition if $\mathrm{C} 2$ capacitor voltage is higher than $\mathrm{C} 3$ then the vectors that should be considered are $0,1 \mathrm{~A}, 2,3,4,5,6,7,8,9,10,12 \mathrm{~A}$, $11,13,14,15,16 \mathrm{~A}, 17,18$. On other hand, if $\mathrm{C} 2$ capacitor voltage is smaller than $\mathrm{C} 3$ capacitor voltage then the vectors that should be considered are $0,1,2,3 \mathrm{~A}, 4,5,6,7 \mathrm{~A}, 8,9,10 \mathrm{~A}$, $11,12,13,14,15,16,17,18$.

TABLE I. VECTORS IN THE FIRST QUADRANT OF VOLTAGE $\alpha \beta$ PLANE CONSIDERING THE SWITCHING COMBINATIONS

\begin{tabular}{|c|c|c|c|c|c|}
\hline$\alpha_{1}$ & $\alpha_{2}$ & $\alpha_{3}$ & $\mathbf{V}_{\alpha}$ & $\mathbf{V}_{\beta}$ & Num. \\
\hline 0.5 & 0 & 0 & $0.41 \mathrm{~V}_{\mathrm{DC}}$ & 0 & $\mathbf{1}$ \\
\hline 1 & 0.5 & 0.5 & $0.41 \mathrm{~V}_{\mathrm{DC}}$ & 0 & $\mathbf{1 A}$ \\
\hline 0.5 & 0.5 & 0 & $0.20 \mathrm{~V}_{\mathrm{DC}}$ & $0.35 \mathrm{~V}_{\mathrm{DC}}$ & $\mathbf{3}$ \\
\hline 1 & 1 & 0.5 & $0.20 \mathrm{~V}_{\mathrm{DC}}$ & $0.35 \mathrm{~V}_{\mathrm{DC}}$ & $\mathbf{3 A}$ \\
\hline 0 & 0.5 & 0 & $-0.20 \mathrm{~V}_{\mathrm{DC}}$ & $0.35 \mathrm{~V}_{\mathrm{DC}}$ & $\mathbf{7}$ \\
\hline 0.5 & 1 & 0.5 & $-0.20 \mathrm{~V}_{\mathrm{DC}}$ & $0.35 \mathrm{~V}_{\mathrm{DC}}$ & $\mathbf{7 A}$ \\
\hline 0 & 0.5 & 0.5 & $-0.41 \mathrm{~V}_{\mathrm{DC}}$ & 0 & $\mathbf{1 0}$ \\
\hline 0.5 & 1 & 1 & $-0.41 \mathrm{~V}_{\mathrm{DC}}$ & 0 & $\mathbf{1 0 A}$ \\
\hline 0 & 0 & 0.5 & $-0.20 \mathrm{~V}_{\mathrm{DC}}$ & $-0.35 \mathrm{~V}_{\mathrm{DC}}$ & $\mathbf{1 2}$ \\
\hline 0.5 & 0.5 & 1 & $-0.20 \mathrm{~V}_{\mathrm{DC}}$ & $-0.35 \mathrm{~V}_{\mathrm{DC}}$ & $\mathbf{1 2 A}$ \\
\hline 0.5 & 0 & 0.5 & $0.20 \mathrm{~V}_{\mathrm{DC}}$ & $-0.35 \mathrm{~V}_{\mathrm{DC}}$ & $\mathbf{1 6}$ \\
\hline 1 & 0.5 & 1 & $0.20 \mathrm{~V}_{\mathrm{DC}}$ & $-0.35 \mathrm{~V}_{\mathrm{DC}}$ & $\mathbf{1 6 A}$ \\
\hline
\end{tabular}

This vectorial modulator does not consider the shoot-through state. This state is related with vector 0 , in which the $\mathrm{AC}$ voltages of the converter are zero. However, there are several vectors associated to this vector. For example, vectors 0 associated to the switching combinations $G_{A}=1, G_{B}=1, G_{C}=$ 1 and $G_{A}=0, G_{B}=0, G_{C}=0$ does not provide shoot-through state. Only the vectors 0 that are associated to the switches in which at least one leg have all the power switches turned-on provides the shoot-through state. Thus, in order to implement this state it will be considered a carrier signal that will be compared with a reference. The result of this comparison will affect directly the state of the switches. Thus, if the reference signal is higher then the carrier, then all the switches will turn on. The reference signal allows to increase or decrease the DC voltage that is applied to the T-Type inverter. Taking this into consideration, the DC voltage will be controlled by a PI compensator that will set the value of the reference signal. The proposed control system is shown in Fig. 4.

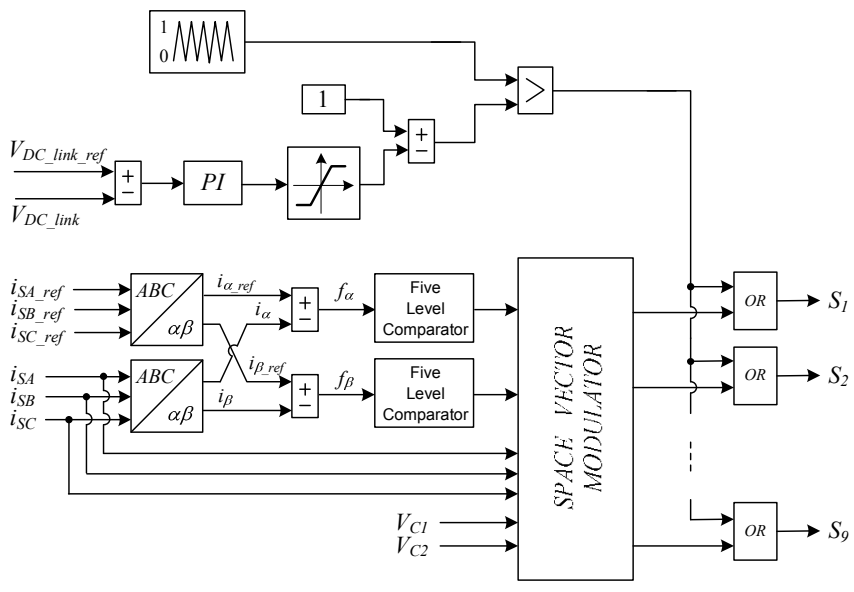

Fig. 4. Proposed Control System.

\section{Simulation RESUlts}

The grid-connected three-phase qZ source inverter with T-type converter using the proposed control system was verified through simulation results. The presented results were obtained through the software Matlab/Simulink. The parameters of the model used in the simulation tests are presented in Table II.

TABLE II. PARAMETERS OF THE SYSTEM

\begin{tabular}{l|c}
\hline Input DC voltage & $200-500 \mathrm{~V}$ \\
\hline Grid RMS voltage & $120 \mathrm{~V}$ \\
\hline Capacitors C1 and C4 & $400 \mu \mathrm{F}$ \\
\hline Capacitors C2 and C3 & $1000 \mu \mathrm{F}$ \\
\hline Inductors L1, L2, L3 and L4 & $200 \mu \mathrm{H}$ \\
\hline Grid inductor LS & $10 \mathrm{mH}$ \\
\hline Grid resistor RS & $0,1 \Omega$ \\
\hline
\end{tabular}

Several simulation tests were firstly performed in steady-state condition. The following results were obtained considering an input DC voltage of $250 \mathrm{~V}$. Fig. 5 shows the grid voltage and $\mathrm{AC}$ current of phase A. From this result is possible to verify that the current presents low distortion and is synchronized with the grid voltage. The three-phase AC currents injected to the grid are presented in Fig. 6. This figure shows that the currents are balanced. Figs. 7 and 8 show the DC voltage applied to the inverter (DC-link) and the phase A to neutral voltage. From these figures is possible to verify the boost capability of the proposed solution, the shoot-through state and also the multilevel operation of the inverter. These results also show that despite the lower voltage of the PV panel the DC-link voltage level is enough to inject currents into the grid with a very low distortion. Fig. 9 shows the voltage at the terminals of capacitors $\mathrm{C}_{2}$ and $\mathrm{C}_{3}$. As can be seen by this last result the voltage balance between the two capacitors is stable. 


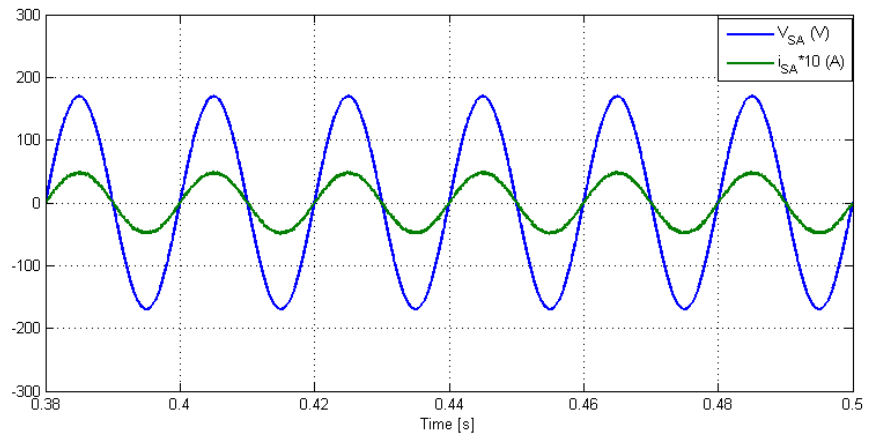

Fig. 5. Simulation result of the grid voltage and AC current of phase A in steady-state condition.

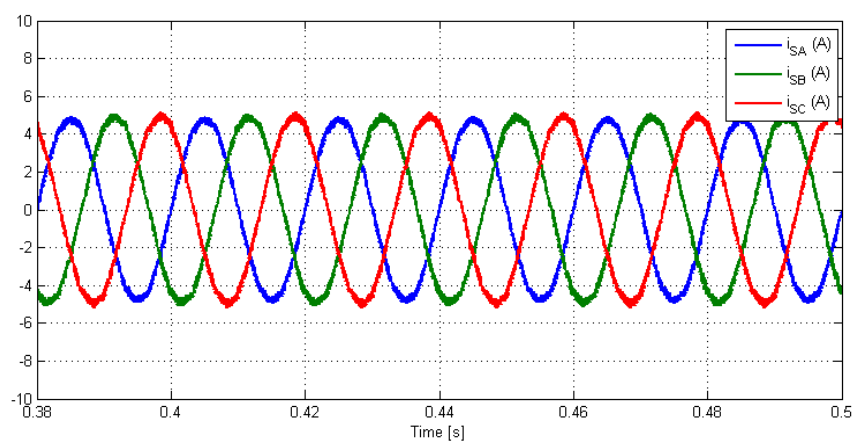

Fig. 6. Simulation result of the three-phase AC currents injected to the grid in steady-state condition.

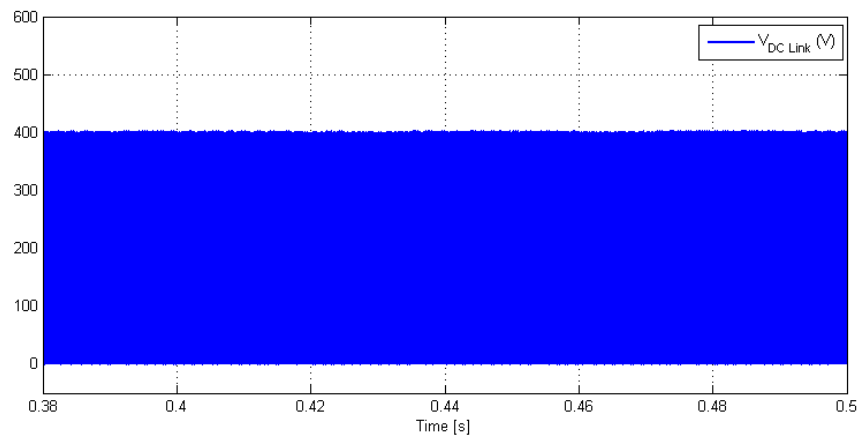

Fig. 7. Simulation result of the DC-link voltage in steady-state condition.

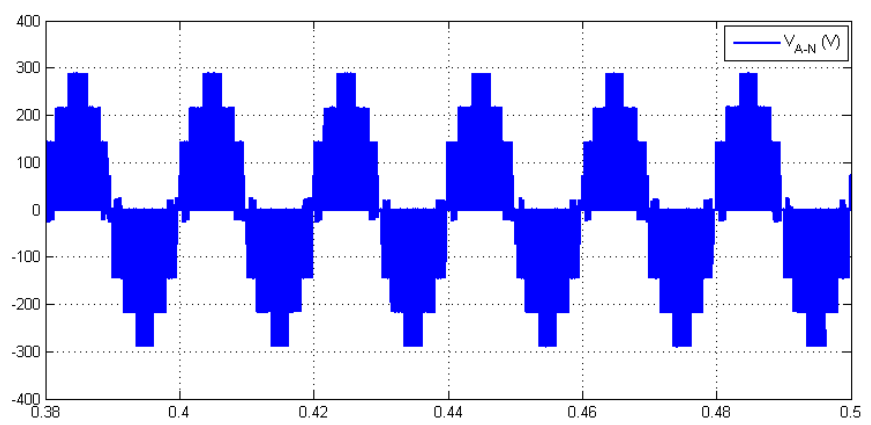

Fig. 8. Simulation result of the Phase A to neutral voltage in steady-state condition.

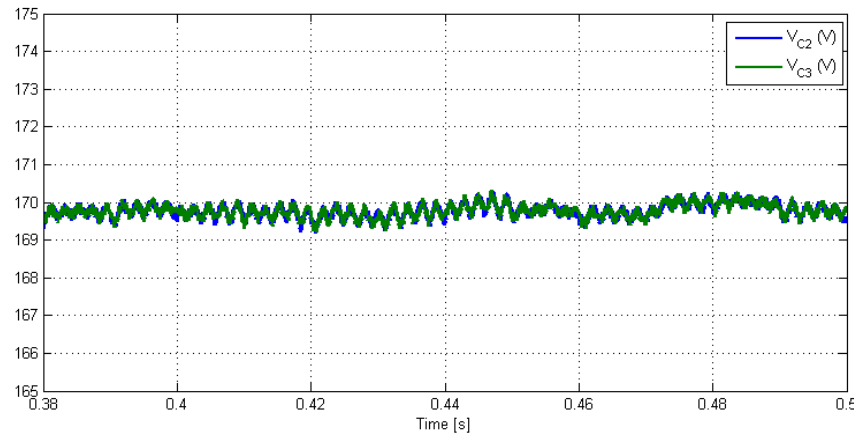

Fig. 9. Simulation result of Capacitors $\mathrm{C}_{2}$ and $\mathrm{C}_{3}$ voltage.

The behavior of the proposed solution in transient mode was also simulated and analyzed and the results can be seen in Figs. 10 and 11. The first result shows the process of DC-link step-up (Boost mode). The DC-link voltage has initially a 275 $\mathrm{V}$ value and at $0.4 \mathrm{~s}$ their reference value is changed to $400 \mathrm{~V}$. Fig. 10 shows the behavior of the grid voltage and current of phase A during the transient. Initially the DC-link voltage is not enough to inject a non distorted current to the grid. However, after the change of the DC-link voltage reference the PI controller also changes the shoot-through duty ratio and consequently the DC-link voltage level to a higher value. Due to this, the DC-link voltage becomes enough to inject a current into the grid with a very low distortion.

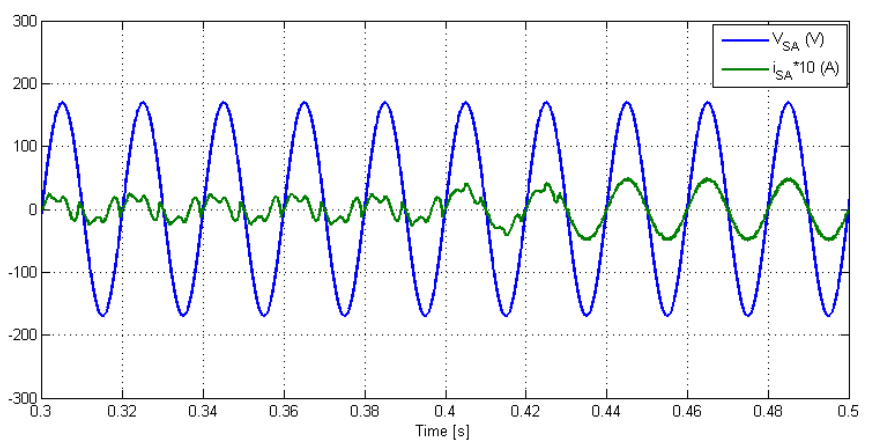

Fig. 10. Transient result for a change in the DC-link voltage: grid voltage and AC current of phase A

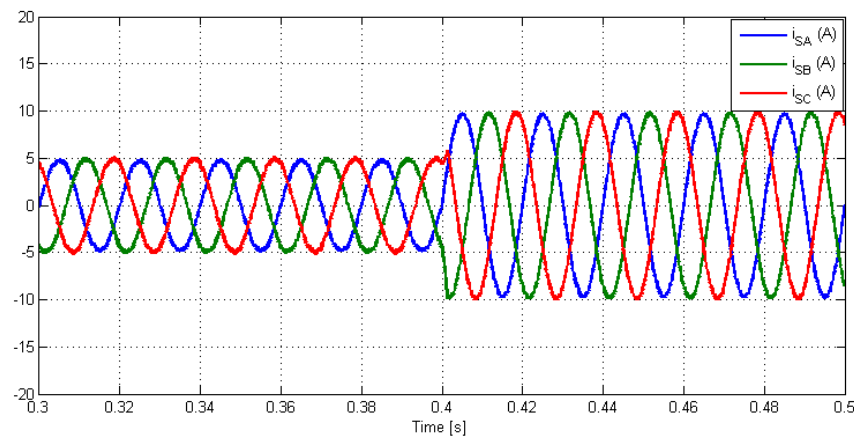

Fig. 11. Transient result for a change in the reference of the AC currents

Fig. 11 shows the transient results for a change in the $\mathrm{AC}$ current references. In this test the reference changes from $5 \mathrm{~A}$ to $10 \mathrm{~A}$ (maximum) at $0.4 \mathrm{~s}$. In this test the DC-link reference 
was fixed in $400 \mathrm{~V}$. Through this result is possible to verify that the currents quickly change to the new reference value, keeping a very low distortion before and after the change.

From the presented results was possible to verify the capability of the proposed closed-loop control. It was possible to verify the fast response of the current controller.

\section{CONCLUSIONS}

This paper proposed a control system for the grid connected three-phase qZ source inverter with T-type converter. The goal of this closed-loop control system is to maintain injected currents to the grid in the reference level with very low distortion, despite variations of the input or grid voltages. The control of the $\mathrm{AC}$ currents where implemented through a fast and robust multilevel hysteretic current controller and vectorial modulator combined with the shoot-through state to provide the necessary step-up voltage. The DC-link voltage is thus controlled through the adjusting the shoot-through duty cycle. Furthermore, the multilevel hysteresis control proposed to this solution presents advantages to renewable energy applications where a wide range regulation of the input voltage capability is required. The characteristics of the proposed system were verified through several results obtained by simulation tests.

\section{ACKNOWLEDGMENT}

This work was supported by national funds through FCT Fundação para a Ciência e a Tecnologia, under projects UID/CEC/50021/2013 and UID/EEA/00066/2013

\section{REFERENCES}

[1] K. H. Ahmed, A. M. Massoud, G. P. Adam, A. F. Zobaa, "A state of the art review of control techniques for power electronics converter based distributed generation systems in different modes of operation", International Conference on Renewable Energy Research and Applications (ICRERA), pp. 1042-1047, October 2013.

[2] E. Can, H. H. Sayan, "SSPWM Three Phase Inverter Design And Experimented On Unbalanced Loads", International Conference on Tehnički Vjesnik, vol. 23, no. 5, pp. 1239-1244, October 2016.

[3] N. Naghizadeh, S. S. Williamson, "A comprehensive review of power electronic converter topologies to integrate photovoltaics (PV), AC grid, and electric vehicles", IEEE Transportation Electrification Conference and Expo (ITEC), pp. 1-6, June 2013.

[4] G. Grandi, D. Ostojic, C. Rossi, D. Casadei, "A New Multilevel Conversion Structure for Grid-Connected PV Applications", IEEE Transactions on Industrial Electronics, vol. 56, $\mathrm{n}^{\mathrm{o}}$. 11, pp. 4416-4426, November 2009.

[5] V. Fernão Pires, J. F. Martins, Chen Hao, "Dual-Inverter for GridConnected Photovoltaic System: Modeling and Sliding Mode Control", Solar Energy, Elsevier, vol. 86, no. 7, pp. 2106-2115, July 2012.

[6] F. Lessa Tofoli, J. C. Schönell, C. A. Gallo, S. M. R. Sanhueza, "A low cost single-phase grid-connected photovoltaic system with reduced complexity", Brazilian Power Electronics Conference, pp. 1033-1038, September 2009.

[7] G. Farivar, B. Hredzak, V. G. Agelidis, "A DC-Side Sensorless Cascaded H-Bridge Multilevel Converter-Based Photovoltaic System", IEEE Transactions on Industrial Electronics, vol. 63, no. 7, pp. 42334241, July 2016.

[8] C. D. Townsend, T. J. Summers, R. E. Betz, "Control and modulation scheme for a Cascaded H-Bridge multi-level converter in large scale photovoltaic systems", IEEE Energy Conversion Congress and Exposition (ECCE), pp. 3707-3714, September 2012.

[9] E. Villanueva, P. Correa, J. Rodriguez, M. Pacas, "Control of a SinglePhase Cascaded H-Bridge Multilevel Inverter for Grid-Connected Photovoltaic Systems", IEEE Transactions on Industrial Electronics, vol. 56, n. 11, pp. 4399-4406, November 2009.

[10] A. Testa, S. De Caro, "Active voltage ripple compensation in PV Systems for domestic uses", IEEE International Symposium on Industrial Electronics, pp. 2193-2198, July 2010.

[11] C.L. Trujillo, F. Santamaría, E.E. Gaona, "Modeling and testing of twostage grid-connected photovoltaic micro-inverters", Renewable Energy, vol. 99, pp. 533-542, December 2016.

[12] M. Cacciato, A. Consoli, N. Aiello, R. Attanasio, F. Gennaro, G. Macina, "A digitally controlled double stage soft-switching converter for grid-connected photovoltaic applications", IEEE Applied Power Electronics Conference and Exposition, pp. 141-147, February 2008.

[13] M.-T. Chen, S.-H. Lin, J.-B. Cai, D.-Y. Chou, "Implementing a singlephase quasi-Z-source inverter with the indirect current control algorithm for a reconfigurable PV system," IEEE International Conference on Industrial Technology (ICIT), pp. 323-328, March 2016.

[14] V. Fernão Pires, Enrique Romero-Cadaval, D. Vinnikov, I. Roasto, J. F. Martins, "Power converter interfaces for electrochemical energy storage systems - A review," Energy Conversion and Management, vol. 86, pp. 453-475, October 2014.

[15] Yam P. Siwakoti; Graham E. Town, "Common-mode voltage reduction techniques of three-phase Quasi Z-Source Inverter for AC drives," Twenty-Eighth Annual IEEE Applied Power Electronics Conference and Exposition (APEC), pp. 2247-2252, March 2013.

[16] S. Bayhan, H. Abu-Rub, "Model predictive control of quasi-Z source three-phase four-leg inverter," 41st Annual Conference of the IEEE Industrial Electronics Society, pp. 362-367, November 2015.

[17] O. Husev, C. Roncero-Clemente, E. Romero-Cadaval, D. Vinnikov, S Stepenko, "Single phase three-level neutral-point-clamped quasi-Z-source inverter," IET Power Electrononics, vol. 8, no. 1, pp. 110, Jan. 2015.

[18] O. Husev, D. Vinnikov, C. Roncero-Clemente, E. Romero-Cadaval, "New Hysteresis Current Control for Grid Connected Single-Phase Three-Level Quasi-Z-Source Inverter," Applied Power Electronics Conference and Exposition, pp. 1765-1770, March 2014.

[19] D. Panfilov, O. Husev, F. Blaabjerg, J. Zakis, K. Khandakji, "Comparison of three-phase three-level voltage source inverter with intermediate dc-dc boost converter and quasi-Z-source inverter," IET Power Electronics, vol. 9, no. 6, pp. 1238-1248, June 2016.

[20] F. Zare, J. A. Firouzjaee, "Hysteresis Phase Band Current Control for a Single Z-source Inverter with Symmetrical and Asymmetrical Znetwork", Power Conversion Conference, pp. 143-148, April 2007.

[21] O. Husev, A. Chub, E. Romero-Cadaval, C. Roncero-Clemente, D. Vinnikov, "Hysteresis current control with distributed shoot-through states for impedance source inverters", International Journal of Circuit Theory and Applications, vol. 44, No. 4, pp. 783-797, April 2016.

[22] Y. Liu, B. Ge, H. Abu-Rub, F. Zheng Peng, "An Effective Control Method for Three-Phase Quasi-Z-Source Cascaded Multilevel Inverter Based Grid-Tie Photovoltaic Power System," IEEE Transactions on Industrial Electronics, vol. 61, no. 12, pp. 6794-6802, December 2014.

[23] D. Sun, B. Ge, X. Yan, D. Bi, H. Zhang, Y. Liu, H. Abu-Rub, L. BenBrahim, F. Z. Peng, "Modeling, Impedance Design, and Efficiency Analysis of Quasi- Z Source Module in Cascaded Multilevel Photovoltaic Power System," IEEE Transactions on Industrial Electronics, vol. 61, no. 11, pp. 6108-6117, November 2014.

[24] V. Fernão Pires, Armando Cordeiro, Daniel Foito, Joao F. Martins, "Quasi-Z-Source Inverter With a T-Type Converter in Normal and Failure Mode", IEEE Transactions on Power Electronics, vol. 31, No. 11, pp. 7462-7470, November 2016.

[25] V. Fernão Pires, Duarte M. Sousa, J. F. Martins, "Controlling a GridConnected T-type Three Level Inverter System Using a Sliding Mode Approach", IEEE International Symposium on Electronics (ISIE 2014), pp 2002-2007, June 1-3, 2014. 